\title{
Web-Based Instruction \& Online Delivery Of Classes: Where Are We Now?
}

Sam Fullerton, Eastern Michigan University, USA

David B. Taylor, University of Waikato, USA

John Watson, St. Bonaventure University, USA

\begin{abstract}
The literature on Web-based instruction (WBI) is reviewed, focusing initially on the terminology, history, and commentary (pro and con) related to the topic. The advantages and disadvantages associated with WBI are then discussed and an overview of the empirical work on WBI, paying particular attention to studies on student satisfaction and learning outcomes, is provided.
\end{abstract}

Key Words: Web-based instruction, online education, distance education, distance learning, synchronous communication, e-learning.

\section{INTRODUCTION}

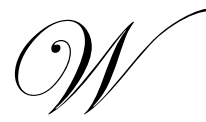

eb-based instruction (WBI) has received considerable scrutiny over the past ten years. It has alternatively been praised and condemned depending upon who was assessing its role in the educational process. To some, it is a major innovation while others simply perceive it to be a new medium by which the educational product can be delivered. Because of its relative newness, the vast majority of the information related to the "product" is anecdotal at best. For example, the media view it as newsworthy to enumerate the perceived pros and cons based solely on the relatively superficial analysis of a few cases. University departmental retreats have become the scene of sharp discourse as supporters and critics often face-off with banter that expresses their strong opinions. And students themselves are often eager to share their opinions with their peers or even with their "traditional" professors. So while there is an undercurrent of discussion regarding the perceived efficacy of online education, most of it is informal at best.

This paper is designed to provide an overview of the commentary and research related to WBI. The review is intended to be comprehensive in nature; as such, it will encompass the terminology associated with distance learning, the history of the area, and alternative applications for WBI. In addition, a number of issues that continue to be scrutinized in the popular and academic press will be discussed. These issues include the advantages and disadvantages associated with WBI as well as the perceived benefits and perceived disadvantages for students. Finally, an overview of the empirical work on WBI will be provided, including studies on student satisfaction and comparisons between learning outcomes derived from WBI in comparison to traditional methods. This portion of the review is extensive, but by no means exhaustive; however, the studies that have been included provide a meaningful representation of the research on online education.

\section{TERMINOLOGY}

Online education is recognized by several designations. One university in the Republic of South Africa refers to "telematics." Another university in New Zealand speaks of "extramural" education when referring to the broad genre of distance learning which presumably includes the delivery of course content via an Internet protocol. Undoubtedly, some administrators view Internet delivery as the future of university education. But, to others, it simply represents the newest method for the delivery of the "old-fashioned correspondence course."

Online education is deemed to fit within the realm of "distance learning." As such, it provides a "structured learning environment in which the teacher and students are separated by time and geographical space 
with some form of technology being used for the transmission of teaching and learning" (Carter, 2001). Clearly, the technology at the heart of the online delivery of the educational product is the Internet and the World Wide Web. A number of terms, including Web-based instruction (WBI) and e-learning have become synonymous with online education. It has also been noted that online education utilizes both the synchronous and asynchronous modes of communication (Eggleston \& Aoki, 1999). The asynchronous mode is typical of the early generation of distance learning whereby two-way communication is not done in real time; rather there is a time delay that precludes immediate feedback. Correspondence course feedback has always been, at least in part, dependent upon the speed of the postal service. Even with today's new technology, feedback may be delayed. For instance, a student's e-mail may languish in the instructor's inbox for some significant period of time before a reply is composed and delivered back to the student. However, the use of the WWW as a medium does provide an opportunity to employ synchronous communications via real-time components such as video conferencing, instant messaging, and realtime chat rooms.

\section{HISTORY OF DISTANCE LEARNING}

It has been stated that "the development of learning resources has always been vital for education" (Imamoglu, 2007). And in fact, the online variation of distance learning may be viewed by many as an extension of the genre of distance learning using newly developed resources which improve both the process and the product. In this regard, this genre is far from new. Formal written correspondence courses were used by various universities as far back as the eighteenth century (Schweizer, 2004). While lagging behind on the adoption curve, the United States university system is believed to have implemented its first correspondence course at Penn State University in 1892 (Banas \& Emory, 1998). More recently, we have witnessed the birth and growth of educational TV in the 1960s, asynchronous PC-based modules in the 1980s, and the synchronous-enabling medium of the Internet in the 1990s (Schweizer, 2004); the virtual classroom was born. Interestingly, the term "virtual classroom" has actually been protected via registration as a unique trademark (Starke-Meyerring \& Clemens, 1999). Regardless of the proprietary nature of the term, the use of the virtual classroom has continued to expand at an extraordinary rate. One estimate is that 50 percent of all higher education students will have taken at least one Web-based instruction course by the year 2007 (Alshare, Kwun \& Grandon, 2006).

\section{APPLICATIONS BEYOND HIGHER EDUCATION}

While higher education represents the bulk of recent Web-based instructional efforts, there has been an extensive and diverse array of applications outside of the formal higher education environment. A few examples include principals in small business enterprises (Imamoglu, 2007), the U.S. Army in its efforts to operationalize military training (Carr, 2000; Banas \& Emory, 1998) as well as for the delivery of college courses to its soldiers (Symonds, 2003), the U. S. government (Banas \& Emory, 1998), and corporations seeking to engrain specific knowledge and skills within their own workforce while concurrently reducing costs and the disruption associated with training that takes place in a centralized location (Schweizer, 2004). But regardless of the composition of any "virtual community," questions regarding advantages, disadvantages, level of satisfaction, and its effectiveness as an educational medium persist. Despite these questions, Web-based instruction is fast becoming a favored option in industry and government (Sitzmann et al., 2006). But nowhere has the diffusion of this innovation been more rapid than it has been in college and university systems worldwide.

\section{CRITICS VS. PROPONENTS: COMMENTARY \& ISSUES}

The literature is replete with examples of harsh commentary regarding the use of the Internet as a tool for the dissemination of the important educational product. Of course, it would not be controversial were it not for the advocates who firmly believe in online education. To many of the proponents, the critics are guilty of a myopic perspective whereby they cannot see the forest for the trees. As early as 1983, well before online education came into vogue, Clark offered the view that the medium used for the delivery of the educational product has no impact on achievement. From this assertion, Palloff and Pratt (1999) inferred that since the Internet is no more than a medium for the delivery of information, its use would have no impact on student achievement. Indeed, the premise that the Internet is simply another medium is repeated in several studies. For these individuals, online education is legitimately viewed as a tool for recruiting students who might not otherwise attend the university (Palloff \& Pratt, 
1999). It is also seen as an effective way to reach new markets of nontraditional students who see WBI as an opportunity to circumnavigate time and location constraints (Confessore, 1999). Consequently, this alternative channel is deemed by many to be an effective strategy for distributing an existing product rather than being viewed as the creation of a new product per se (Vamosi, Pierce \& Slotkin, 2004). Today's mainstream marketers would simply view it as a market penetration strategy, one that facilitates the marketing of an existing educational product to the university's current target markets. Despite this rationale, the naysayers continue to put forth an array of criticisms that illustrate the magnitude of the difference of the opinions held by the advocates and the critics. Consider the following explicit examples of criticism directed toward online education in general. The comments allow the reader to grasp the essence of Confessore's (1999) statement that the so-called virtual university, "replete with the dazzling accoutrements of the information revolution has recently been the subject of bitter debate."

Perhaps the harshest statement is that "e-teaching...can pose moral threats to the legitimacy of the educational process" (Stahl, 2004). Another quote from an anonymous Georgetown University professor compares online education to "a new version of a trade school" while labeling it as the "joke of the $21^{\text {st }}$ century" (Confessore, 1999). In this same article, a York University professor characterized it as "pedagogically meaningless." Despite such harsh assessments, Confessore indicates that faculty attitudes "seem to be mellowing." More recently, McPherson and Nunes (2006) noted an indication that professors will embrace it once it is not seen as a "detriment to their profession or careers." Still, it is reported that the "perception of college professors toward those (Webbased instruction) programs is significantly less favorable than are the perceptions of the college students" (Wilkes, Simon \& Brooks, 2006).

Another line of criticism focuses on questions surrounding the eagerness of educational institutions to add online courses to augment the array of options for students. Perhaps the most compelling criticism is predicated upon the belief that they are nothing more than "cash cows" for the institutions (Carr-Chellman, 2000). This concern led Stahl (2004) to question whether the drive for increased revenue outweighs the educational mission, a concern also shared by many students.

Among the remaining common criticisms that stoke the fire of controversy is the concern that Internetbased learning is not based upon a sound pedagogical framework (Jom, Duin, \& Wahlstrom, 1996), a dilemma which is further complicated by the limited choice of classes available to students (Mihhailova, 2006). Perhaps it is this limited selection that has led some critics to indicate a concern that the students may be taking courses for the wrong reasons, thus lacking interest and commitment for the courses in which they are ultimately enrolled (Carr-Chellman, 2000). In this regard, Alexander (1997) stated a concern that the education industry has adopted what is tantamount to a production orientation and that it needs to focus more on student goals rather than on the new technologies that are now available. In fact, the technology itself represents a source of concern on the part of those who worry that online education is simply "information dispensation rather than interaction," a condition that most certainly undermines the effectiveness of teaching and the extent of student learning (Carr-Chellman, 2000). Further compounding this concern is the commonly held belief that there has been an absence of scrutiny regarding the quality of Web-based instruction (Peltier, Drago \& Schibrowsky, 2003) as well as the general determinants of student satisfaction and dissatisfaction (Chyung \& Vachon, 2005). It is issues such as these that lower the students' perceptions of quality thereby resulting in their reluctance to fully embrace online education (Mihhailova, 2006).

A final controversial issue involves the legitimacy of on-line universities. These schools offer no courses through the traditional mode of delivery; rather their entire array of course offerings and programs is delivered solely via an Internet-based medium. The warning is somber; put succinctly, we are told to be aware of the reality that "some universities, and even some of the organizations that accredit them, are bogus" (Anon, 2007).

\section{PERCEIVED ADVANTAGES AND BENEFITS ACCRUING TO HIGHER EDUCATION STUDENTS}

The literature identifies a host of potential benefits that the online student may reap. The most commonly mentioned benefit is that of accessibility and convenience (Vamosi, Pierce \& Slotkin, 2004). As such, Web-based instruction (WBI) has been characterized as quick and easy (Sitzmann et al., 2006), a just-in-time (JIT) delivery system (Marks, Sibley \& Arbaugh, 2005), a time-saver that eliminates commuting (Marks, Sibley \& Arbaugh, 2005), a flexible alternative regarding the students' use of their time (Fujii, Yukita, Koike, \& Kunii, 2004; 
Demirdjian, 2002), and a flexible alternative regarding student location (Fujii et al., 2004; Carr-Chellman, 2000). This flexibility is further supported by Mihhailova's (2006) statement that there is "no need for a physical presence" on the part of the student. As such, convenience and accessibility are deemed to represent "most of the advantage" afforded by distance learning such as that which is operationalized via the Internet (Carr-Chellman, 2000).

A second commonly discussed advantage of WBI is that of diversity (Larson, 1999). As more students are allowed to enroll, it has been stated that WBI offers more "democratic access" to university courses and programs (Carr-Chellman, 2000). As the virtual classroom transcends regional and national boundaries, cultural diversity is more likely to exist (Alshare, Kwun \& Grandon, 2006). To that end, it can legitimately be argued that the resultant cultural diversity enhances both the formal and the informal learning environments in which the students virtually coexist.

While not necessarily an advantage over traditional classroom instruction, e-learning does possess one key advantage over the earlier modes of delivery for distance education - that of immediacy. The advanced technology provides a mechanism by which immediate feedback can be generated (Graham \& Scarborough, 1999). Clearly, this advantage can be attributed to the synchronous nature of the system which facilitates direct interaction among members of the virtual community by using tools such as chat rooms or an instant messaging protocol (Schweizer, 2004; Kulik \& Kulik, 1988).

There are a number of additional advantages that also receive mention, albeit at a nominal level, in the literature. Among them are lower commuting costs (Demirdjian, 2002) and the potential for lower tuition fees as a result of the economies of scale achieved by the university (Demirdjian, 2002). Related to the cost consideration is the ability of the students to complete courses without suffering lost wages due to time away from work (Larson, 1999). This concurrently allows students to enroll in classes they might otherwise have missed, to take courses that fit their personal goals from other institutions, and to perhaps graduate earlier (Marks, Sibley \& Arbaugh, 2005). Web-based delivery can feature customized content (Sitzmann et al., 2006), a benefit that may resonate with corporations seeking to enroll their employees in relevant executive education programs. But as easily as it can be customized, it can be standardized so as to insure the consistency of training everywhere throughout the world (Sitzmann et al., 2006).

It is worth noting that this section set out to enumerate "perceived advantages and benefits." Despite the substantial list offered here, many critics will debate their very existence. Stahl (2004) summed up their skepticism best with the statement that "the most general critique of e-teaching is that it does not live up to the promises listed in the preceding paragraphs." With that thought in mind, attention will now be directed toward the persistent criticisms that raise doubts as to the efficacy of online education.

\section{PERCEIVED DISADVANTAGES FOR STUDENTS}

Though many different terms have been used to denote the concept of online education, one of the most common is that of "e-learning." By far the most frequently mentioned shortcoming of e-learning is the diminished interaction between the teacher and the student. While acknowledging that the synchronous components of WBI have enhanced the ability to generate real-time feedback and discussion, there are still commonly used asynchronous components which hinder the ability of these individuals in the virtual classroom to achieve the important interaction that has long been the hallmark of the traditional classroom (Wegerif, 1998). Consider the following citations which support Marks, Sibley and Arbaugh's (2005) premise that the reduced level of teacher-student interaction is the most important deficiency endured by students in an online class. In further articulating this concern, Mihhailova (2006) indicates her belief that the biggest problem is that there is "no direct contact" and further notes the "loss of the teacher's aura" that is associated with online education. Navarro and Shoemaker (1999) indicated the same concern, that WBI "may eliminate" the sought interaction. While their assertion is dated, especially for a domain marked by rapid advances in technology, it is evident that some of the more recent research has continued to put forth this concern. For example, in comparison to traditional classes, interaction in the virtual classroom has been characterized as lower (Vamosi, Pierce \& Slotkin, 2004), much lower (Chyung \& Vachon, 2005) and weak (Rahm \& Reed, 1997; Sonner, 1999). 
Compounding the problem of reduced teacher-student interaction is the reality that demands for immediate feedback have created unrealistic expectations on the part of students, especially in light of the fact that asynchronous components such as e-mail and threaded discussions still play a key role (Tricker et al., 2001). Two articles indicated that many students expect to have access to their teachers 24/7, an obviously unrealistic expectation, yet one that can lead to dissatisfaction (Greco, 1999; Banas \& Emory, 1998). Furthermore, when immediate feedback is available via synchronous components such as Web casts and chat rooms, some students are simply reluctant to participate (Siritongthaworn \& Krairit, 2006).

A second aspect of interaction is that which occurs among the peers in the class. Thus, another criticism that surfaces is the reduced level of student-to-student interaction. Although this concern is not as pronounced as it is with regard to the student-teacher relationship, it is still viewed as a potential problem that serves to make WBI less meaningful to students (Sitzmann et al., 2006). This assertion is consistent with earlier studies which tended to characterize this form of interaction as weak (Rahm \& Reed, 1997; Sonner, 1999).

The third disadvantage is related to the first two. Many authors decry what might be deemed the lack of human touch. Perhaps at the forefront of this concern is the reality that asynchronous communication is still widely used as part of the delivery process (Demirdjian, 2002). Again, there is mention of the absence of live interaction and the "lack of personal contact" (Carr-Chellman, 2000). Even more compelling are the depiction of the students' "isolation" (Gregory, 2003; Banas \& Emory, 1998) and the "dehumanization" of the process that is characterized by repetition, delayed feedback, and the loss of student focus (Demirdjian, 2002). Another reality is that no form of distance learning is appropriate for courses which demand human intervention in a personal manner (Mihhailova, 2006). Examples of this unsuitability could be courses such as personal selling and music. Further compounding this problem is the belief that the lack of human touch may result in a lack of commitment on the part of the student (Carr-Chellman, 2000) thereby resulting in a negative impact on learning.

Given the self-directed nature of distance learning, it is evident that more pressure will be placed on students regarding time management. An early study of student preferences indicated that students preferred the traditional classroom setting because WBI was deemed to be less efficient (Welton, 1997). In fact, a second article indicated the students' belief that they are required to invest more time for an online course than they would for the same course taught in a traditional classroom environment (Oliver \& Omari, 1999). Vamosi, Pierce and Slotkin (2004) noted the students' belief that time management was an issue that created inefficiency in the learning process, perhaps related to the assertion that it is easy "to be lazy" when taking an online course (Mihhailova, 2006).

With greater connectivity, faster transmission speeds, more user-friendly software and hardware, one might expect technology issues to be a non-factor today. Unfortunately, the review of the literature reveals more concerns to have been recently put forth in comparison to the early days of WBI. Early on, it was duly noted that students had to possess a specific set of technical skills in order to be able to take full advantage of this form of delivery (Banas \& Emory, 1998). Perhaps even more problematic was the fact that when the inevitable technical glitches occurred, students often had no single point of contact where they could go to seek resolution (Banas \& Emory, 1998). Sitzmann et al. (2006) still recognize the issue regarding the students' technology skills. Also, with today's streaming capabilities, more questions are being raised about the existence of sufficient bandwidth for the transmission of large files in a timely manner (Schweizer, 2004; Sitzmann et al., 2006). Siritongthaworn and Krairit (2006) likewise questioned the efficiency of today's operating systems as students seek faster connections to facilitate the opening of documents as well as the uploading and downloading of data files. As a rejoinder of sorts, it should also be noted that there is a belief that recent advances in technology have enhanced the ease of use for today's students (Imamoglu, 2007). Still, in light of increased usage and more reports of hackers, there is a legitimate concern as to potential breaches of security that might result in the compromising of personal information (Ramim \& Levy, 2006).

One last potential disadvantage for students is the universities' historical reliance on adjuncts to staff online courses (Confessore, 1999). However, as online classes are becoming more mainstream, more academically qualified professors are stepping into the virtual classroom. Additionally, some of the criticism of the adjuncts may be unwarranted as many of these individuals fit the various accreditation bodies' definition of "professionally qualified" thereby indicating that they are knowledgeable conduits of educational insight. 


\section{BROAD OVERVIEW OF STUDIES OF STUDENTS WHO HAVE TAKEN ONLINE COURSES}

While much of our discussion has focused on general commentary about WBI, there is a growing body of empirical work designed to move beyond the anecdotal. These studies are delineated in the following paragraphs and can be categorized into two areas-studies concerning student satisfaction and those concerning student learning. A total of 21 studies will be discussed. Of those, 16 were undertaken in the United States. The earliest of these articles was published in 1997 while the most recent was in 2007. The five non-US studies were all recently completed; they took place in Australia (Dixon, Pelliccione \& Dixon, 2005), Estonia (Mihhailova, 2006), Taiwan (Lee, 2007), Thailand (Siritongthaworn \& Krairit, 2006), and Turkey (Imamoglu, 2007). Nineteen of the 21 focused on university students while one, Roblyer (1999), examined high school and community college students and another, the Turkish study by Imamoglu (2007), examined the attitudes of small business practitioners regarding the perceived usefulness of e-learning. The 19 university-oriented studies were based on actual experience, and of these, 12 involved business students. The remaining seven looked at students in education (Welton, 1997; Dixon, Pelliccione \& Dixon, 2005; Chyung \& Vachon, 2005), sociology (Schutte, 1997), biology (Sanders \& MorrisonShetler, 2001), library science (Gregory, 2003), and students across a broad array of majors (Lee, 2007).

Having identified these key studies, it is now time to explore the extent to which students reported that they were satisfied with their online learning experiences. The following sections also feature additional articles that are cited in studies which used meta-analysis as the basis for making determinations as to which variables have a direct relationship with either student satisfaction or student learning. The demographic influences on satisfaction and learning will also be discussed.

\section{STUDENT SATISFACTION}

Questions regarding student satisfaction began to surface as early as 1993 (Goodwin), but the primary concern at that time was focused on the technology. Furthermore, when simply looking at broad measures of satisfaction, the results are inconsistent. Oliver and Omari (1999) reported positive responses as did the more recent study by Mihhailova (2006) which likewise indicated a general level of satisfaction. Conversely, lower levels of satisfaction were reported by Terry, Owens and Macy (2001), Ponzurick, France, and Logar (2000), and Vamosi, Pierce and Slotkin (2004). Additional insight was provided by Peltier, Drago, and Schibrowsky (2003) who indicated that student satisfaction is a function of the level and quality of interaction with their teacher and fellow students. Cornell and Martin (1997) reported a correlation between satisfaction and the ease of use of the online system. Three studies noted higher dropout rates for online classes (Aron, 1999; Roblyer, 1999; Peltier, Drago \& Schibrowsky, 2003). Intuitively, it would seem fair to assume that it is some element of dissatisfaction that leads to the propensity of students to abandon their online classes.

The literature on satisfaction also provides empirical support for the earlier assertion that the diminished level of student-teacher interaction is a problem which adversely affects the level of satisfaction reported by the student. One study indicated that the synchronous WBI classes exhibited levels of satisfaction that were equivalent to those attained in traditional courses; yet the same study reported significantly higher levels of satisfaction with hybrid courses than with those delivered entirely online (Gregory, 2003). Similarly, Dixon, Pelliccione, and Dixon (2005) stated that the synchronous content of hybrid classes established them as a superior mode of delivery when compared to the DEO (Distance Education Only) model. This belief is supported by Siritongthaworn and Krairit (2006) who state that satisfaction is a function of the delivery method (DEO versus hybrid) and the facilitation of communication (synchronous versus asynchronous). Further support is provided by Arbaugh (2001) in his discussion of "social distance." According to his research on "immediacy behaviors," a reduction in social distance between the teacher and the student will result in higher levels of satisfaction. Thus, the use of synchronous components such as chat rooms and video conferencing which enhance both student-to-student and student-toteacher interaction are viewed as techniques by which student satisfaction can be enhanced (Gunawardena, Lowe \& Anderson, 1997).

Another study of interest concerns the relationship between involvement and satisfaction with WBI courses. Smith, Ferguson \& Caris (2001) found that students who have taken more courses using a Web-based 
format tend to exhibit higher levels of satisfaction (i.e., greater involvement with online courses is associated with higher levels of satisfaction).

Despite the abundance of research on student satisfaction, no single measure which captures the phenomenon has been developed. However, in a move in that direction, an "e-learner satisfaction scale" has been proposed (Wang, 2003). As online education continues to become more widespread, such measures are inevitable. But as of now, student satisfaction continues to be measured primarily by the use of the same course evaluation surveys that are commonly used in the traditional classroom.

Undoubtedly, educators would prefer to believe that students will be more satisfied if they feel that have learned the material. This presumption leads to the next component of the literature review, that of student learning outcomes.

\section{LEARNING OUTCOMES}

In an era of assessment and the corresponding focus on student outcomes, it is evident that questions regarding student learning will need to be answered. Several studies have already sought to measure the students' levels of learning. Perhaps not surprisingly, just as there were conflicting reports regarding the online students' levels of satisfaction, the same is true of reports that purportedly measure their levels of learning.

Some studies compare online learning and traditional classroom instruction while others seek to draw a line of demarcation between online learning and other forms of distance education. Five early studies reported that there was no discernable difference in the level of learning by students in online classes and those who took the course in the traditional classroom instruction format (Gregory, 2003; Dellana, Collins \& West, 2000; Russell, 1999; Sonner, 1999; Welton, 1997). Even more encouraging results were reported in two studies which indicated the achievement of higher levels of learning in the DEO format (Sitzmann et al., 2006; Schutte, 1997). It is conceivable that the aforementioned results are meaningful enough to counter Terry, Owens, and Macy's (2001) conclusion that "students perform better in traditional classes than in virtual ones." Efforts to compare WBI to other forms of distance learning also support the efficacy of e-learning. Three studies reported levels of learning for students enrolled in WBI classes were as high, if not higher, than those of students who were enrolled in more traditional formats of distance learning (Sitzmann et al., 2006; Zhao et al., 2005).

Just as "immediacy behaviors" had a positive impact on student satisfaction, it has been further noted that such a reduction in the "social distance" between the professor and the student can lead to higher learning achievement by the students (Arbaugh, 2001). Another finding is that DEO classes work well for cognitive-learning oriented courses that stress memorization, but not for behavior-based courses such as personal selling or courses that emphasize physical skills such as art (Taylor 2002). Recognizing the importance of the learning phenomenon, Peltier, Drago, and Schibrowsky (2003) have developed a model for measuring course effectiveness which is based on the realization that there are "multiple drivers of the virtual communities' effectiveness."

\section{DEMOGRAPHIC INFLUENCES ON SATISFACTION AND LEARNING}

Perhaps some of those drivers just alluded to are student demographics. To this point in time, there have been relatively few studies that have sought to determine the nature of the relationship between the characteristics of the students and the effectiveness of online courses as measured by satisfaction and learning outcomes. Three studies have reported that age, gender, and grade point average (GPA) seem to impact neither the propensity to enroll in a WBI course (Parnell \& Carraher, 2003; Roblyer, 1996) nor the students' performance in one (Marks, Sibley, \& Arbaugh, 2005). However, a more recent study reported that women were less likely to enroll in a WBI course (Wilkes, Simon \& Brooks, 2006). Interestingly, it was alternatively reported that women held more favorable attitudes about WBI than did their male counterparts (Sanders \& Morrison-Shetler, 2001). That same study also reported that younger students were more favorably predisposed to WBI courses than were their older counterparts (although it should be noted that the "oldest" group was defined as students over the age of 23). So while there are a few studies that have examined the role of student demographics in this educational model, the paucity of research is compounded by the fact that the results of these studies are, to some extent, contradictory. 


\section{CONCLUSIONS}

It is clear that WBI plays a significant role in contemporary education. The reality is that we are in the midst of a significant paradigm shift; online education is here to stay. It is also clear that research on WBI is in its infancy, and a more rigorous examination of the relationships and variables underpinning the area is required. Educators have used technology to enhance the learning environment in the past, and it is their responsibility to identify when WBI is most appropriate and beneficial to both the student and the institution. In order to reach that objective, a significant amount of work needs to be done as there are currently far more questions than answers surrounding WBI. Questions such as the following need to be addressed. 1) What are the primary variables driving satisfaction for WBI? 2) Is WBI more effective for students in specific fields of study? 3) In what situations does WBI lead to enhanced learning? 4) In what situations is a traditional classroom or a hybrid situation best for learning?

Although many people have opinions about WBI, it is time to focus discussion on more reasoned analysis based on empirical work rather than anecdotal evidence. When that time comes, we will have a far better idea about what WBI's role in education should be.

\section{AUTHOR INFORMATION}

Sam Fullerton is a Professor of Marketing at Eastern Michigan University. Dr. Fullerton has written books on professional selling and marketing research. His most recent book, Sports Marketing, was published by McGrawHill/Irwin. Dr. Fullerton's research in business and consumer ethics, sports marketing, and cross-cultural comparisons of consumer attitudes has been published in the Journal of Business Ethics, Strategic Management Journal, Sport Marketing Quarterly, and Psychology and Marketing. Dr. Fullerton earned a Ph.D. in Marketing from Michigan State University and an M.S. in Marketing from Memphis State University.

David Taylor is an Associate Professor of Marketing at Waikato University. His research on direct marketing and marketing within small and medium-sized firms has been published in the European Journal of Marketing, Journal of International Marketing and Marketing Research, Marketing Intelligence and Planning, and the European Business Review. He has served on the Editorial Review Board of the Journal of Consumer Behaviour and earned an MA from Lancaster University.

John Watson is a visiting Associate Professor of Marketing at St. Bonaventure University. Dr. Watson's research on consumer values and ethnocentrism has been published in the Journal of Business Research, European Journal of Marketing, Journal of Consumer Affairs, Psychology and Marketing, and the Journal of Economic Psychology. Dr. Watson earned a Ph.D. in Marketing from the Pennsylvania State University and an M.S. in Business Administration from Bucknell University.

\section{REFERENCES}

1. Alexander, S. (1997). Teaching and Learning on the World Wide Web, Ausweb95: First Australian World Wide Web Conference, http://elmo.scu.edu.au/sponsored/ausweb/ausweb95/ (accessed January 21, 2007).

2. Alshare, K., Kwun, O., and Grandon, E. (2006). Determinants of instructors' intentions to teach online courses: a cross-cultural perspective, The Journal of Computer Information, 46(3), 87-95.

3. Anonymous (2007). Web Site Ranks Top 20 Online Colleges, Online Universities, www.online-colleges-anddegrees.com (accessed March 29, 2007).

4. Arbaugh, J. (2001). How instructor immediacy behaviors affect student satisfaction in web-based courses, Business Communication Quarterly, 64(4), 42-54.

5. $\quad$ Aron, L. (1999). Online U, Across the Board, 36(8), 63-66.

6. Banas, E. and Emory, W. (1998). History and issues of distance learning, Public Administration Quarterly, 22(3), 365-383.

7. Carr, S. (2000). Army plans to offer laptops and distance education to all soldiers, Chronicle of Higher Education, http://chronicle.com/free/2000/07/20000700lu.htm, accessed February 4, 2007).

8. Carr-Chellman, A. (2000). Distance education: A reflective action research project and its systematic implications for higher education, Journal of Systemic Practice and Research, 13(4), 587-612. 
9. Carter, A. (2001). Interactive distance education implications for the adult learner, International Journal of Instructional Media, 28(3), 24-26.

10. Chyung, S. and Vachon, M. (2005). An investigation of the profiles of satisfying and dissatisfying factors in elearning, Performance Improvement Quarterly, 18(2), 97-113.

11. Clarke, R. (1983). Reconsidering research on learning from media, Review of Educational Research, 53(4), 445459.

12. Confessore, N. (1999). The virtual university, The New Republic, 221(14), 26-28.

13. Cornell, R. and Martin, B. (1997). The role of motivation in web-based instruction, in Kahn, B. (editor), Webbased Instruction, Educational Technology Publications, Englewood Cliffs, NJ, 93-100.

14. Dellana, S. Collins, W., and West, D. (2000). Online education in a management science course - Effectiveness and performance factors, Journal of Education for Business, 76(1), 43-47.

15. Demirdjian, Z. (2002). The virtual university: Is it a panacea or Pandora's box? Journal of American Academy of Business, 1(2), 172-178.

16. Dixon, K., Pelliccione, L., and Dixon, R. (2005). Differing student views of online learning modes across two programs in an Australian university, Campus-Wide Information, 22(3), 140-147.

17. Eggleston, C. and Aoki, K. (1999). Collaboration technologies, http://www.rit.edu/cpe4937/collab/collab tech.html, (accessed January 21, 2007).

18. Fujii, N., Yukita, S., Koike, M., and Kunii, T. (2004). An e-learning system based on the top-down method and the cellular models, International Journal of Distance Education Technologies, 2(4), 77-93.

19. Goodwin, B. (1993). A study of the perceptions and attitudes exhibited by distance education students and faculty at the University of Phoenix online program, doctoral dissertation, Dissertation Abstracts International, University of Arizona, (55).

20. Graham, M. and Scarborough, H. (1999). Computer-mediated communication and collaborative learning in an undergraduate distance learning environment, Australian Journal of Educational Technology, 15(1), 20-46.

21. Greco, J. (1999). Going the distance for MBA candidates, Journal of Business Strategy, 20(3), 30-34.

22. Gregory, V. (2003). Student perceptions of the effectiveness of Web-based distance education, New Library World, 104(10), 426-431.

23. Gunawardena, C., Lowe, C. and Anderson, T. (1997). Interaction analysis of a global online debate and the development of a constructivist interaction analysis model for computer conferencing, Journal of Educational Computing Research, (17), 395-429.

24. Imamoglu, S. (2007). An empirical analysis concerning the user acceptance of e-learning, Journal of American Academy of Business, 11(1), 132-137.

25. Jom, L., Duin, A., and Wahlstrom, B. (1996). Designing and managing virtual learning communities, IEEE Transactions on Professional Communication, (39)4, 183-191.

26. Kulik, J. and Kulik, C. (1988). Timing of feedback and verbal learning, Review of Educational Research, 58, 7997.

27. Larson, N. (1999). Distance learning: Linking the globe through education, World Trade, 12(12), 74-79.

28. Lee, Y. (2007). Understanding e-learning consumers: the moderating effects of gender and learner diversity, Journal of the American Academy of Business, 11(1), 223-230.

29. Marks, R., Sibley, S. and Arbaugh, J. (2005). A structural equation model of predictors for effective online learning, Journal of Management Education, 29(4), 531-563.

30. McPherson, M. and Nunes, M. (2006). Organizational issues for e-learning: Critical success factors as identified by HE practitioners, International Journal of Educational Management, 20(7), 542-558.

31. Mihhailova, G. (2006). E-learning as internationalization strategy in higher education: Lecturer's and student's perspective, Baltic Journal of Management, 1(3), 270-284.

32. Navarro, P. and Shoemaker, J. (1999). The power of cyberlearning: An empirical; test, Journal of Computing in Higher Education. 11(1), 29-54.

33. Oliver, R. and Omari, A. (1999). Using online technologies to support problem-based learning: Learners' responses and perceptions, Australian Journal of Educational Technology, 151(5), 8-79.

34. Palloff, R. and Pratt, K. (1999). Building learning communities in cyberspace: Effective strategies for the online classroom, Jossey-Bass, San Francisco, CA.

35. Parnell, J. and Carraher, S. (2003). The Management Education by Internet Readiness (MEBIR) Scale: Developing a scale to assess personal readiness for Internet-mediated management education, Journal of Management Education, (27), 431-446.

36. Peltier, J., Drago, W. and Schibrowsky, J. (2003). Virtual communities and the assessment of online marketing education, Journal of Marketing Education, 25(3), 260-276. 
37. Ponzurick, T., France, K. and Logar, C. (2000). Delivering graduate marketing education: An analysis of face-toface versus distance education, Journal of Marketing Education, 22(3), 120-128.

38. Rahm, D. and Reed, B. (1997). Going remote: The use of distance learning, the World Wide Web, and the Internet in graduate programs of public affairs and administration, Public Productivity and Management Review, 20(4), 459-471.

39. Ramim, M. and Levy, Y. (2006). Securing e-learning systems: A case of insider cyber attacks and novice IT management in a small university, Journal of Cases on Information Technology, 8(4), 24-35.

40. Roblyer, M. (1999). Is choice important in distance learning? A study of student motives for taking Internetbased courses at the high school and community college levels, Journal of Research on Computing in Education, (32) Fall, 157-171.

41. Russell, T. (1999). The no significant difference phenomenon, Distance Education Review, http://tenb.mta.ca/phenom/phenom.html, (accessed March 19, 2004).

42. Sanders, D. and Morrison-Shetler, A. (2001). Student attitudes toward Web-enhanced instruction in an introductory biology course, Journal of Research on Computing in Education, 3(33), 251-262.

43. Schweizer, H. (2004). E-learning in Business, Journal of Management Education, (28)6, 674-692.

44. Schutte, J. (1997). Virtual teaching in higher education: The new intellectual superhighway or just another traffic jam? http://www.csun.edu/sociology/virexp.htm, (accessed January 21, 2007)

45. Siritongthaworn, S. and Krairit, D. (2006). Satisfaction in e-learning: The context of supplementary instruction, Campus-Wide Information Systems, 23(2), 76-91.

46. Sitzmann, T., Kraiger, K., Stewart, D., and Wisher, R. (2006). The comparative effectiveness of web-based and classroom instruction: A meta-analysis, Personnel Psychology, 59(3), 623-664.

47. Smith, G., Ferguson, D., and Caris, M. (2001). Teaching college courses: Online versus face-to-face, T.H.E. Journal, 28(9), 18-24.

48. Sonner, B. (1999). Success in capstone business course: Assessing the effectiveness of distance learning, Journal of Education for Business, (74) (March-April), 243-247.

49. Stahl, C. (2004). E-teaching - the economic threat to the ethical legitimacy of education? Journal of Information Systems Education, 15(2), 155-162.

50. Starke-Meyerring, D. and Clemens, L. (1999). Theoretical and practical considerations for virtual learning environments in technical communication: An annotated bibliography, Technical Communications Quarterly, $8(2), 125-141$.

51. Symonds, W. (2003). eArmyU, BusinessWeek, 106.

52. Taylor, R. (2002). Pros and cons of online learning - a faculty perspective, Journal of European Industrial Training, 26(1), 24-37.

53. Terry, N., Owens, J., and Macy, A. (2001). Student performance in the virtual versus formal classroom, Journal of the Academy of Business Education, 2(1), 1-4.

54. Tricker, T., Rangecroft, M., Long, P., and Gilroy, P. (2001). Evaluating distance education courses: The student perception, Assessment \& Evaluation in Higher Learning, 26(2), 165-177.

55. Vamosi, A., Pierce, B., and Slotkin, M. (2004). Distance learning in an accounting principle course - student satisfaction and perceptions of efficacy, Journal of Education for Business, 79(6), 360-366.

56. Wang, Y. (2003). Assessment of learner satisfaction with asynchronous learning systems, Information and Management, 41(1), 75-86.

57. Wegerif, R. (1998). The social dimension of asynchronous networks, Journal of Asynchronous Networks 2.1, http://www.aln.org/alnweb/journal/vol2_issue1/wegerif.htm, (accessed January 22, 2007)

58. Welton, D. (1997). Student perceptions of learning, efficiency, and usability of CDES 272 Web-based instruction, http://www.butte.cc.ca.us/-dgwelton/272evav.index.html, (Accessed January 21, 2007).

59. Wilkes, R., Simon, J., and Brooks, L. (2006). A comparison of faculty and undergraduate students' perceptions of online courses and degree programs, Journal of Information Systems Education, 17(2), 131-140.

60. Zhao, Y., Lei, J., Lai, B., and Tan, H. (2005). What makes a difference? A practical analysis of research on the effectiveness of distance education, Teachers College Record, (107), 1836-1884. 